\title{
Severe refractory congestive cardiac failure in an elderly man
}

\author{
B O’Neill, H Taggart
}

An 80-year-old man presented with a two-week history of anorexia, malaise, peripheral and scrotal oedema and shortness of breath. He had no cardiac history and consumed very little alcohol. He had been active prior to the onset of symptoms and had been playing golf regularly.

Clinical examination revealed a sinus tachycardia of 112 beats $/ \mathrm{min}$, a jugular venous pressure of $5 \mathrm{~cm}$, and no cardiac murmurs. The abdomen was distended and the liver was enlarged six fingerbreadths; there was marked sacral, leg and scrotal oedema. The congestive cardiac failure responded poorly to high-dose frusemide.

Chest X-ray showed cardiomegaly and slight blunting of the left costophrenic angle. The electrocardiogram was normal apart from sinus tachycardia. Blood tests revealed haemoglobin $10 \mathrm{~g} / \mathrm{dl}$, mean corpuscular volume $109 \mathrm{fl}$, iron studies showed an iron diversion picture; alkaline phosphatase $439 \mathrm{U} / 1$ (normal 90-280), aspartate transaminase $98 \mathrm{U} / 1$ (2-35), gamma glutamyl transferase $138 \mathrm{U} / \mathrm{l}(5-60)$, alanine transaminase $33 \mathrm{U} / \mathrm{l}$, bilirubin $19 \mu \mathrm{mol} / \mathrm{l}$. Transthoracic echocardiography revealed normal valvular function and an ejection fraction of $60 \%$ (figure).

Department of Health Care for the Elderly, Belfast City Hospital, Lisburn Road, Belfast BT9 $7 A B$, Northern Ireland B O'Neill H Taggart

Correspondence to Dr H Taggart

Accepted 28 February 1996

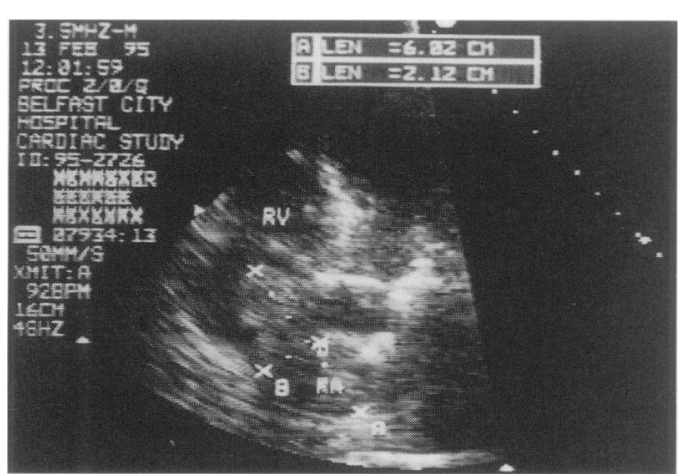

\section{Questions}

1 What abnormality is shown (outlined by crosses) in the right atrium on the echocardiogram?

2 Name four possible causes for this.

Figure 
Answers

QUESTION 1

A tumour $(6 \times 3.5 \mathrm{~cm})$ obstructing right ventricular flow.

QUESTION 2

Atrial myxoma; direct tumour spread from hepatocellular carcinoma, renal cell carcinoma or leiomyosarcoma of inferior vena cava.

\section{Discussion}

Atrial myxoma is rare and usually involves the left atrium (75\%) although $18 \%$ of cases occur in the right atrium. Secondary cardiac tumours are 20-40 times more common. ${ }^{1}$ The short history with extensive oedema in a previously healthy elderly man was unusual. A silent myocardial infarction was ruled out. Echocardiography proved invaluable in elucidating the cause of the cardiac failure. A large tumour mass was found obstructing the right atrium which had spread directly from the inferior vena cava. Hepatocellular carcinoma, renal cell carcinoma and leiomysarcoma of the inferior vena cava can all present this way.

His enlarged liver, which was thought to be due to the cardiac failure, was found on ultrasound examination to be infiltrated with tumour. The report mentioned metastases as the likely cause but autopsy later revealed primary hepatocellular carcinoma. A small percentage $(1-4 \%)$ of these tumours will

1 Hall R, Cooley D, McAllister H, et al. Neoplastic heart disease. In: Schlant $\mathbf{R}$, Alexander $\mathbf{R}$, eds. The heart, arteries and veins. New York: McGraw-Hill, 1994; pp 2007-27.

2 Morimoto K, Matsui R, Hashimoto $\mathrm{T}$, et al. Intra-atrial extension of hepatocellular carcinoma detected with ultrasound. F Clin Ultrasound 1986; 14: 466-9.

3 Huang CS, Chen MR, Liang D-C, et al. Right atrial metastasis of hepatocellular carcinoma. $f$ Clin Ultrasound 1993; 21: 335-8.

\section{Learning points}

- consider secondary cardiac tumour in patients with congestive cardiac failure which responds poorly to therapy

- echocardiology is useful in diagnosing previously unsuspected tumours in the heart

spread to the heart, although there have been few reports in the literature and nearly all are from the Far East. ${ }^{2-4}$

Conventional therapy for cardiac failure is likely to be relatively ineffective as in this case. Prognosis is generally very poor although Maskai ${ }^{5}$ reported a patient who survived eight months after cardiac surgery to remove the tumour. Our patient died four weeks after hospital admission.

\section{Final diagnosis}

Congestive cardiac failure due to direct tumour spread to the inferior vena cava and right atrium from primary hepatocellular carcinoma.

Keywords: cardiac failure, hepatocellular carcinoma, atrial myxoma, echocardiography

We acknowledge the assistance of Dr Peter Ingram, Department of Pathology, Dr SG Richardson, Consultant Cardiologist, Department of Cardiology, Belfast City Hospital, and Miss Andree Best for typing the manuscript.

4 Chia BL, Choo M-H, Tan L, et al. Two dimensional echocardiographic abnormalities of right atrial metastatic tumours in hepatoma. Chest 1985; 87: 399-401.

5 Masaki N, Hayashi S, Maruyama T, et al. Marked clinical improvement in patients with hepatocellular carcinoma by surgical removal of extended tumour mass in right atrium and pulmonary arteries. Cancer Chemother Pharmacol 1994; 33: S7-S11.

Although no entry was $100 \%$ correct, the two clear winners of the Christmas Quiz were: Dr JP Bourke (Palmerston North, New Zealand)

Dr RJ Shekarappa (Chicago, USA)

The Editor congratulates the winners, who will each receive a free subscription to the Postgraduate Medical Journal for 1997 